\title{
Erratum
}

\section{A comparison of photosynthesis in two thalloid liverworts}

T.G.A. Green and W.P. Snelgar

Oecologia (Berlin) (1982) 54:275-280

Table 4 of the manuscript on page 278 did not appear in its complete form. The complete version should have been as follows:

Table 4. Summary of resistance analyses and photosynthetic rates

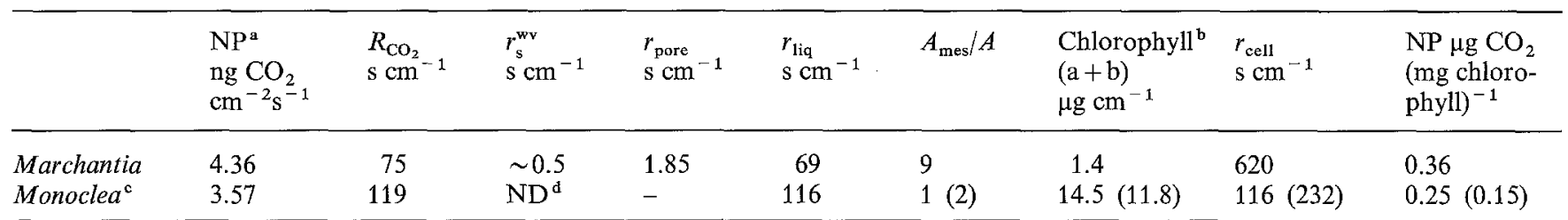

a At $200 \mu \mathrm{E} \mathrm{m}^{-2} \mathrm{~s}^{-1}, 15^{\circ} \mathrm{C}, 330 \mu 1 \mathrm{CO}_{2} 1^{-1}$, mean of all measurements $(n=9)$

b Calculated on a mesophyll area basis

c Calculated assuming $\mathrm{CO}_{2}$ enters only through the upper surface. Values in parentheses are for two sided calculation

d ND - value below level of detection with porometer 